\title{
Pelargonium graveolens Aqueous Decoction: A New Water-Soluble Polysaccharide and Antioxidant-Rich Extract
}

\author{
Malek Ennaifer $\mathbb{D}^{1,},{ }^{1,2}$ Taroub Bouzaiene, ${ }^{1}$ Moncef Chouaibi, ${ }^{2}$ and Moktar Hamdi ${ }^{1}$ \\ ${ }^{1}$ University of Carthage, Institut National des Sciences Appliquées et de Technologie (INSAT), 1080 Tunis, \\ Tunisia_LETMI - INSAT, Tunisia \\ ${ }^{2}$ Higher Institute of Food Industry, Tunis (ESIAT), Tunisia \\ Correspondence should be addressed to Malek Ennaifer; malekgo@yahoo.fr
}

Received 26 July 2018; Accepted 29 October 2018; Published 12 November 2018

Guest Editor: Alladdin El Salabi

Copyright (C) 2018 Malek Ennaifer et al. This is an open access article distributed under the Creative Commons Attribution License, which permits unrestricted use, distribution, and reproduction in any medium, provided the original work is properly cited.

\begin{abstract}
Background. The decoction of Pelargonium graveolens yields an antioxidant-rich extract and a water-soluble polysaccharide. This study aims (1) to investigate the effect of process parameters (extraction time and temperature) on the antioxidant activity of the decoction and the extraction yield of CPGP by response methodology and (2) to study the chemical properties of the optimized decoction and rheological properties of the corresponding extracted polysaccharide. Results. The antioxidant-rich decoction contained about $19.76 \pm 0.41 \mathrm{mg} \mathrm{RE} / \mathrm{g}$ DM of flavonoids and $5.31 \pm 0.56 \mathrm{mg} \mathrm{CE} / \mathrm{gDM}$ of condensed tannins. The crude Pelargonium graveolens polysaccharide (CPGP) contained $87.27 \%$ of sugar. Furthermore, the CPGP solutions $(0.5 \%, 1 \%$, and $2 \%)$ exhibited shear-thinning or pseudoplastic flow behavior. A central composite design (CDD) was applied to assess the effects of temperature and time on the antioxidant activity of the decoction, on the one hand, and on water-soluble polysaccharide yield, on the other. The decoction optimization of Pelargonium graveolens aimed to use less energy $\left(93^{\circ} \mathrm{C}\right.$ for 11 minutes) leading to the highest values of decoction phenolic content $(33.01 \pm 0.49 \mathrm{mg} \mathrm{GAE} / \mathrm{gDM})$ and DPPH scavenging activity $(136.10 \pm 0.62 \mathrm{mg}$ TXE/gDM) and the highest values of CPGP yield (6.97\%). Conclusion. The obtained results suggest that the CPGP rheological characteristics are suitable for applications in many industries, especially food. The values of optimal conditions showed that Pelargonium graveolens decoction operation could have multiple uses, especially for consuming less energy.
\end{abstract}

\section{Introduction}

Pelargonium graveolens is a herb belonging to the Geraniaceae family and it has good aromatic properties. It is cultivated worldwide $[1,2]$, mainly for its essential oil fraction, which is extensively used in many industries. The essential oil of the fresh plant is widely used in perfume industry thanks to its desirable scent [3]. Besides, many studies on active molecules in essential oil and organic extracts of Pelargonium graveolens have shown good antioxidant activity and antimicrobial effect, especially against $B$. cereus, B. subtilis, and $S$. aureus [4-6]. However, because of the toxicity of essential oils and organic extracts, their application in food against spoilage pathogens is limited, and more interest in safety matters should be shown [7].

In Tunisia, rose-scented geranium is broadly used to produce a food flavoring hydrosol used in traditional pastries.
Some studies have proven its good antioxidant activity and capacity to heal throat pains [8]. Nevertheless, after distillation, the used plant is considered as waste. The decoction uses the whole plant and exhibits the presence of many active compounds such as phenolics $[9,10]$. Yet, to our knowledge, little is known about the phytochemical composition and biological activities of Pelargonium graveolens decoction even though it is an ancestral practice used for its extract digestibility and safety compared to essential oils [10]. Moreover, decoctions are still used and even optimized to improve their added-value products $[9,11]$. Decoction optimization parameters include temperature extraction, time extraction [9], $\mathrm{pH}$, and the ratio of water to raw material [11]. Optimization was performed using experimental designs to produce response surfaces that were also widely used to determine optimal conditions to extract polysaccharides from different sources [12-14] and different processes [15]. Although most of new 
water-soluble polysaccharide extraction operations start with a decoction $[14,16,17]$, no special interest has been given to both optimal extraction parameters leading to an addedvalue decoction and a maximum yield of its water-soluble polysaccharide.

This study aims (1) to investigate the effect of process parameters (extraction time and temperature) on the antioxidant activity of the decoction and the extraction yield of CPGP by response methodology and (2) to study the chemical properties of the optimized decoction and rheological properties of corresponding extracted polysaccharide.

\section{Material and Methods}

2.1. Plant Material and Sampling. Geranium aerial parts were harvested from a random sample of a plant growing in Ariana (North of Tunisia: latitude $36^{\circ} 51^{\prime} 36^{\prime \prime} \mathrm{N}$, longitude $10^{\circ} 11^{\prime} 36^{\prime \prime} \mathrm{E}$, altitude $10 \mathrm{~m}$ ) in April 2014. Leaves, flowers, and stems were manually isolated from the branches to obtain a weight of 1.00 $\mathrm{kg}$ and dried at $20^{\circ} \mathrm{C}$ for 2 weeks. A specimen was kept in our unit as a reference.

2.2. Chemicals. All chemicals were purchased from Sigma, Tunisia.

2.3. Decoction Operation. Dried ground Pelargonium graveolens whole plant (stems, flower, and leaves) (10 g) was extracted with distilled water (ratio of water to raw material $(\mathrm{ml} / \mathrm{g})$ was 10:1), while the water temperature was maintained at a given temperature (within $\pm 2^{\circ} \mathrm{C}$, extraction temperature ranging from 78 to $98^{\circ} \mathrm{C}$ ) for a given time (extraction time ranging from 8 to $20 \mathrm{~min}$ ) (Figure 1). The flask was then cooled and the mixture was then filtered over a Buchner funnel. The decoction was prepared in triplicate. The resulting decoctions were stored at $4^{\circ} \mathrm{C}$ for future use.

2.4. Crude Polysaccharide Extraction. After decoction centrifugation, a volume of ethanol was added to the supernatant. The mixture was shaken overnight at room temperature (400 $\mathrm{mo} / \mathrm{min})$. Then, the solution was centrifuged for a quarter of an hour $\left(4^{\circ} \mathrm{C} ; 3500 \mathrm{rpm}\right)$; the resulting precipitate was collected; the crude Pelargonium graveolens polysaccharide (termed CPGP) was obtained. The extract was air dried at $40^{\circ} \mathrm{C}$ until constant weight (Figure 1). The CPGP yield (\%) was calculated by the equation [18]:

$$
\text { CPGP yield }(\%)=\frac{m_{0}}{m} \times 100
$$

where $\mathrm{m}_{0}(\mathrm{~g})$ is the dried CPGP weight and $\mathrm{m}(\mathrm{g})$ is the dried raw material (DM) weight.

2.5. Optimization of Decoction. The central composite design (CDD) was applied to study the effect of temperature (X1) and time (X2) on the total phenolic content (Y1), DPPH essay (Y2), and yield of CPGP (Y3) as responses. The experimental factors and levels are shown in Table 1. The coded levels and experimental value of each factor, in each experience, are shown in Table 2.

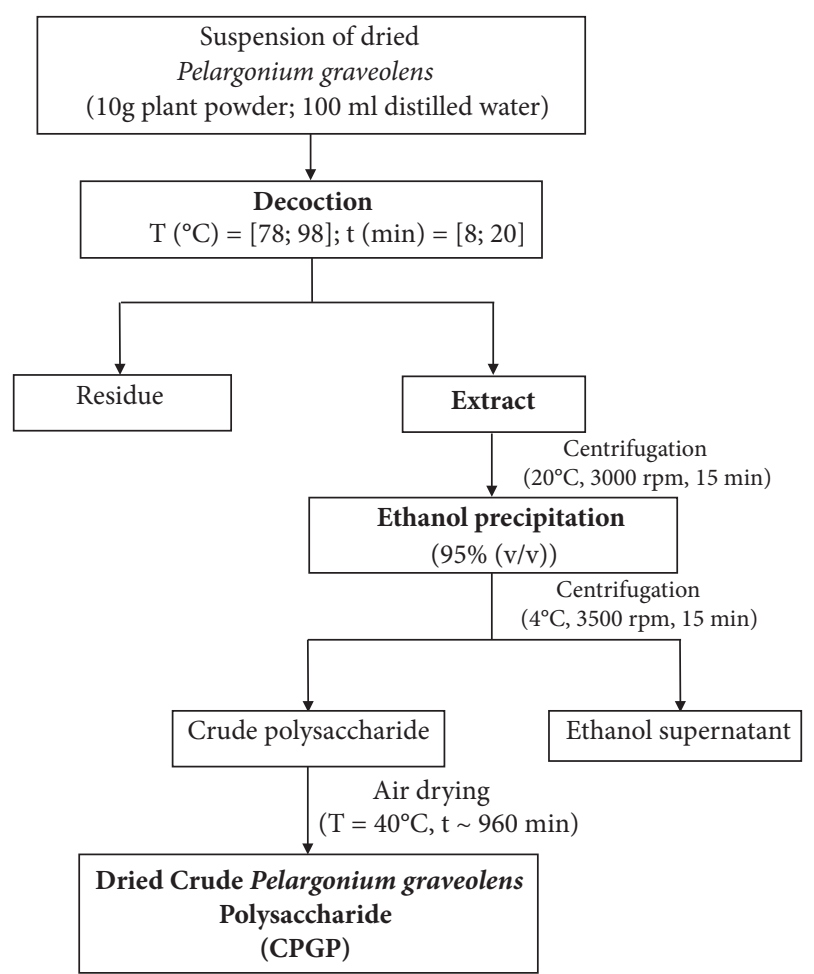

FIgURE 1: Process of Pelargonium graveolens decoction and polysaccharide extraction.

The polynomial model used to express the responses was

$$
\begin{aligned}
\mathrm{Y}= & \mathbf{b} 0+\mathbf{b} 1 * \mathrm{X} 1+\mathbf{b} 2 * \mathbf{X} 2+\mathrm{b} 11 *(\mathrm{X} 1 * \mathrm{X} 1) \\
& +\mathbf{b} 22 *(\mathrm{X} 2 * \mathrm{X} 2)+\mathrm{b} 12 *(\mathrm{X} 1 * \mathrm{X} 2)
\end{aligned}
$$

where $\mathrm{Xi}$ represents the level of the factor $\mathrm{i}, \mathrm{Y}$ is the experimental response, and $\mathrm{b}$ is a parameter of the model (regression coefficient).

Every model parameter has a precise meaning: b0 represents the response analyzed at the domain center; the values of b1 and b2 indicate the importance of the effects of the factors (temperature and time, respectively) on the responses; b12 is an interaction parameter between the two factors. The values of b11 and b22 determine the movement of the response surface (upward for positive values or downward for negative values) [9].

\subsection{Physical Chemistry of the Decoction}

2.6.1. Total Phenolic Content. The Folin-Ciocalteu method [19] was used to assess the total phenolic content. The phenol contents were expressed as milligrams of Gallic acid equivalent per gram of dry matter (mg GAE/gDM).

2.6.2. Flavonoid Contents. The colorimetric method [20] was used to measure the flavonoid contents. Briefly, $0.5 \mathrm{~mL}$ of each diluted extract was mixed with $0.5 \mathrm{~mL}$ of $2 \% \mathrm{AlCl}_{3}$ methanol solution. After $30 \mathrm{~min}$ incubation, the absorbance was read at $430 \mathrm{~nm}$. Flavonoid contents were calculated from a calibration curve of rutin and expressed as milligrams of 
TABLE 1: Experimental factors and their levels in CCD.

\begin{tabular}{|c|c|c|c|c|c|c|}
\hline & & & & & & \\
\hline & & & Levels & & & \\
\hline Factor & Unit & -1 & 0 & 1 & $-\alpha$ & $+\alpha$ \\
\hline (X1) Extraction temperature & ${ }^{\circ} \mathrm{C}$ & 81 & 88 & 95 & 78 & 98 \\
\hline (X2) Extraction time & $\min$ & 10 & 14 & 18 & 8 & 20 \\
\hline
\end{tabular}

${ }^{*} \alpha=1.41$.

TABLE 2: Central composite design for the decoction: temperature and time, with observed responses (total phenolic content, DPPH scavenging activity, and crude Pelargonium graveolens polysaccharide yield).

\begin{tabular}{|c|c|c|c|c|c|c|c|}
\hline \multirow[t]{3}{*}{ TEST } & \multicolumn{4}{|c|}{ Factors } & \multicolumn{3}{|c|}{ Responses } \\
\hline & \multicolumn{2}{|c|}{ X1 } & \multicolumn{2}{|c|}{$\mathrm{X} 2$} & \multirow{2}{*}{$\begin{array}{c}\text { Y1 } \\
\text { Total phenolic } \\
\text { content (mg } \\
\text { GAE/gDM) }\end{array}$} & \multirow{2}{*}{$\begin{array}{c}\text { Y2 } \\
\text { DPPH } \\
\text { scavenging } \\
\text { activity (\%) }\end{array}$} & \multirow{2}{*}{$\frac{\text { Y3 }}{\text { CPGP yield }(\%)}$} \\
\hline & $\begin{array}{c}\text { Temperature } \\
\left({ }^{\circ} \mathrm{C}\right)\end{array}$ & Coded level & Time (min) & Coded level & & & \\
\hline 1 & 81 & -1 & 10 & -1 & 28.24 & 72.9 & 3.48 \\
\hline 2 & 95 & 1 & 10 & -1 & 36.04 & 81.93 & 8.97 \\
\hline 3 & 81 & -1 & 18 & 1 & 30.37 & 65.13 & 4.11 \\
\hline 4 & 95 & 1 & 18 & 1 & 36.36 & 85.92 & 7.78 \\
\hline 5 & 88 & 0 & 14 & 0 & 30.79 & 68.7 & 7.25 \\
\hline 6 & 88 & 0 & 14 & 0 & 33.8 & 77.2 & 4.99 \\
\hline 7 & 78 & -1.41 & 14 & 0 & 27.05 & 60.5 & 4.06 \\
\hline 8 & 98 & 1.41 & 14 & 0 & 36.54 & 88.44 & 8.21 \\
\hline 9 & 88 & 0 & 8 & -1.41 & 32.27 & 79.41 & 5.64 \\
\hline 10 & 88 & 0 & 20 & 1.41 & 32.4 & 76.47 & 7.33 \\
\hline 11 & 88 & 0 & 12 & -0.5 & 31.64 & 73.11 & 4.68 \\
\hline 12 & 88 & 0 & 16 & 0.5 & 31.63 & 83.19 & 5.48 \\
\hline 13 & 84 & -0.5 & 14 & 0 & 26.86 & 67.65 & 3.69 \\
\hline 14 & 92 & 0.5 & 14 & 0 & 34.42 & 81.3 & 5.95 \\
\hline 15 & 79 & -1.3 & 12 & -0.5 & 28.47 & 65.69 & 3.43 \\
\hline 16 & 97 & 1.3 & 16 & 0.5 & 35.54 & 83.82 & 6.93 \\
\hline
\end{tabular}

rutin equivalent per gram of dry matter (mg RE/gDM). The results are means of triplicates.

2.6.3. Total Condensed Tannins. To measure the condensed tannins, the vanillin assay [21] was performed. To $50 \mu \mathrm{l}$ of diluted sample, a volume of methanol vanillin solution (3 $\mathrm{ml}, 4 \%)$ and a volume of $\mathrm{H}_{2} \mathrm{SO}_{4}(1.5 \mathrm{ml})$ were added. After a $15 \mathrm{~min}$ reaction, the absorbance was read at $500 \mathrm{~nm}$. The methanol was used as a blank. The amount of total condensed tannins was expressed as milligrams of catechin equivalent per gram of dry matter (mg CE/gDM). All samples were analyzed in three replications.

2.6.4. Free Radical Scavenging Activity. The DPPH (2,2diphenyl-1-picrylhydrazyl) radical scavenging capacity was measured [22]. Briefly, $50 \mu \mathrm{L}$ of a double serial dilution of the aqueous extracts were mixed to $0.95 \mathrm{~mL}$ of $60 \mu \mathrm{M} \mathrm{DPPH}$ radical solution and left away from light for $30 \mathrm{~min}$. The spectrophotometer was set at $517 \mathrm{~nm}$. The percentage of radical inhibition (I \%) was estimated as

$$
\mathrm{I} \%=100 \times \frac{\left(\mathrm{A}_{0}-\mathrm{A}_{1}\right)}{\mathrm{A}_{0}}
$$

where $A_{0}$ is the control absorbance and $A_{1}$ is the sample absorbance. All tests were triplicated. For the optimized decoction extract, the DPPH activity was calculated from a calibration curve of Trolox and expressed as milligrams of Trolox equivalent per gram of dry matter (mg TXE/gDM).

2.6.5. Color Measurement. The CIELAB coordinates (L*, $\mathrm{a} *, \mathrm{~b} *$ ) were measured in a Minolta colorimeter (Minolta, Model CM-3600 d, UK) controlled by a computer that calculated color from the reflectance spectrum [23]. The L* parameter (lightness index) ranges from 0 (black) to 100 (white). However, the a* parameter indicates the degree of red $(+a *)$ or green $(-a *)$ colors, whereas the $b *$ parameter measures the degree of the yellow $(+b *)$ or blue $(-b *)$ colors. Samples were poured in Petri dishes till the brim and placed on the device sensor.

2.7. Sugar Content, FTIR Spectra, and Rheology of CPGP Solutions. The Pelargonium graveolens decoction was first treated with the Sevag reagent to eliminate any resulting proteins [24]. Next, the supernatant was dialyzed for three days and, finally, the CPGP was precipitated using ethanol 
TABLE 3: Parameters of the polynomial models representing the studied responses (Y1-Y3).

\begin{tabular}{|c|c|c|c|c|c|c|}
\hline \multirow{2}{*}{$\begin{array}{l}\text { Model } \\
\text { Model parameters }\end{array}$} & \multicolumn{2}{|c|}{ Y1 } & \multicolumn{2}{|c|}{$\mathrm{Y} 2$} & \multicolumn{2}{|c|}{ Y3 } \\
\hline & Coefficient & $P$ value & Coefficient & $P$ value & Coefficient & $P$ value \\
\hline b0 & 32.524 & $* * *$ & 77.720 & $* * *$ & 4.937 & $* * *$ \\
\hline b1 & 3.911 & $* * *$ & 8.227 & $* * *$ & 1.702 & $* * *$ \\
\hline b2 & 0.224 & n.s & -0.503 & n.s & 0.195 & n.s \\
\hline b11 & -0.161 & n.s & -1.976 & n.s & 0.446 & n.s \\
\hline b22 & 0.032 & n.s & 0.277 & n.s & 0.738 & $*$ \\
\hline b12 & -0.442 & n.s & 2.508 & n.s & -0.562 & n.s \\
\hline \multicolumn{7}{|l|}{ Model validation } \\
\hline Significance level (\%) & \multicolumn{2}{|c|}{$* * *$} & \multicolumn{2}{|c|}{$* * *$} & \multicolumn{2}{|c|}{$* * *$} \\
\hline Df & \multicolumn{2}{|c|}{13} & \multicolumn{2}{|c|}{13} & \multicolumn{2}{|c|}{13} \\
\hline Sum of squares & \multicolumn{2}{|c|}{$1.28 \mathrm{E}+02$} & \multicolumn{2}{|c|}{$9.16 \mathrm{E}+02$} & \multicolumn{2}{|c|}{42.341} \\
\hline Mean square & \multicolumn{2}{|c|}{24.04} & \multicolumn{2}{|c|}{$1.66 \mathrm{E}+02$} & \multicolumn{2}{|c|}{7.673} \\
\hline $\mathbf{R}^{2}$ & \multicolumn{2}{|c|}{0.949} & \multicolumn{2}{|c|}{0.910} & \multicolumn{2}{|c|}{0.902} \\
\hline Adjusted $\mathrm{R}^{2}$ & \multicolumn{2}{|c|}{0.918} & \multicolumn{2}{|c|}{0.854} & \multicolumn{2}{|c|}{0.847} \\
\hline
\end{tabular}

$* * *$ : Significant at the level $99.9 \%$

$* *$ : Significant at the level $99 \%$

$*$ : Significant at the level $95 \%$

n.s: not significant

Df: degrees of freedom.

(V/V). The obtained crude polysaccharide was dried at $40^{\circ} \mathrm{C}$ until constant weight, then suspended in distilled water to measure the sugar content [18]. For the FTIR test, the CPGP was rather lyophilized than dried before spectroscopy experiment.

2.7.1. Sugar Content. The phenol-sulphuric method was used [25]. The purity (\%) of CPGP is calculated as the sugar content of extraction per dried crude polysaccharide weight.

2.7.2. Fourier Transform Infrared Spectroscopy. The Fourier Transform Infrared (FTIR) method was used to characterize CPPG by a VERTEX 70 (Bruker Optics, USA) spectrometer. The decoction was further deproteinized by the Sevag reagent (a mixture of $\mathrm{CHCl}_{3}$ and $\mathrm{n}$-butanol, $\mathrm{v} / \mathrm{v}=4: 1$ ). The aqueous fraction was precipitated by adding ethanol. The mixture was centrifuged and the crude polysaccharide (the precipitate) was then suspended in water and dialyzed for three days. The precipitate was lyophilized. The FTIR spectral bonds ranged from 500 to $4000 \mathrm{~cm}^{-1}$.

2.7.3. Viscosity Measurement. The flow behavior of different CPGP water solutions $(0.5 ; 1$ and $2 \%)$ was measured by a strain-controlled rheometer (AR 2000, TA Instruments, Ltd., Crawley, UK). The viscosity was measured at a temperature of $20^{\circ} \mathrm{C}$ and shear rates between $10 \mathrm{~s}^{-1}$ and $1000 \mathrm{~s}^{-1}$. Flow behavior was determined by the power law model:

$$
\sigma=k \gamma^{\mathrm{n}}
$$

where $\sigma$ is the shear stress $(\mathrm{Pa}), \gamma$ is the shear rate $(1 / \mathrm{s}), \mathrm{n}$ is the flow index, and $\mathrm{k}$ is the consistency index.
2.8. Statistical Analysis. The statistical analysis was performed using one way analysis of variance (ANOVA) followed by Duncan's test for the means comparisons and a $P$ value of less than 0.05 was considered significant.

\section{Results}

3.1. Optimization of the Decoction of Pelargonium graveolens. There were 16 runs for optimizing the five individual parameters in the current CDD design (Table 2). The data were analyzed by multiple regression analysis using NEMRODW (9901- by LPRAI_Marseille, France) and each response was studied separately.

3.1.1. Model Validation. The statistical analysis checks the existence of coefficients which do not influence responses. A good and correct description of the model variation of the test results can be affirmed when the significance shown in the tables of the analysis of variance is superior to 95\% [2628].

Table 3 lists the obtained results of the statistical test, the estimated values of the model coefficients, and the model validation parameters. For response Y1, only 2 parameters were significant in decoction process. Thus, total phenolic content of the decoction could be given by the equation:

$$
\mathrm{Y} 1=32.524+3.191 \mathrm{X} 1
$$

According to this equation, the temperature may have a linear effect on the total phenolic content. For response Y2, 2 out of the 6 model parameters were significant in decoction process. Similarly to the case of the response Y1, the coefficients b2-b12 do not influence the response since these coefficients' value of 
significance is less than $95 \%$. Thus, the decoction antioxidant activity could be given by the equation:

$$
\mathrm{Y} 2=77.72+8.227 \mathrm{X} 1
$$

According to this equation, the temperature may have a linear effect on the DPPH scavenging activity. The statistical analysis for response Y3 shows that only three parameters were significant in decoction process. Thus, polysaccharide yield extract from the decoction could be given by the equation:

$$
\mathrm{Y} 3=4.937+1.702 \mathrm{X} 1+0.738(\mathrm{X} 2 . \mathrm{X} 2)
$$

According to this equation, the temperature may have a linear effect on CPGP yield. However, the extraction time may have a quadratic effect on the same response.

\subsubsection{Extraction Parameters Influence on Decoction Total Phe-} nolic Content. According to the positive linear coefficient of (5) (+3.191), the phenolic content reaches higher values with increase in extraction temperature. This can be observed in Figure 2(a), showing the contour plots for phenolic content. The area of the experimental domain shows that, independent of time, the amount of total phenolics reaches its maximum for a temperature interval between $88^{\circ} \mathrm{C}(\mathrm{X} 1=0.5)$ and $98^{\circ} \mathrm{C}$ $(\mathrm{X} 1=+\alpha)$. Within this interval, about $37 \%$ of phenolic content is obtained (Figure 2(a)_3D surface plot).

\subsubsection{Extraction Parameters Influence on Decoction Scav-} enging Activity. As time is kept constant, a difference in temperature increases the scavenging activity. Figure 2(b) shows that the scavenging activity reaches its maximum for a temperature extraction interval between $88^{\circ} \mathrm{C}(\mathrm{X} 2=0.5)$ and $98^{\circ} \mathrm{C}(\mathrm{X} 2=+\alpha)$. The time of extraction would have an impact only for extreme temperature.

\subsubsection{Extraction Parameters Influence on Crude Pelargonium} graveolens Polysaccharide Yield. According to (7), the time and temperature of the extraction increase the CPGP yield. Figure 2(c) shows that the yield of polysaccharide CPGP reaches its maximum at an interval of temperature between $95^{\circ} \mathrm{C}(+1)$ and $98^{\circ} \mathrm{C}(+\alpha)$, regardless of decoction time.

\subsubsection{Predicted and Experimental Optimal Condition of Total} Phenolic and CPGP Contents. The main objective of this study is to look for the optimum parameters values which help to enhance the decoction antioxidant activity and the corresponding polysaccharide yield. Tables 4 and 5 present optimal conditions and predicted variables. In an experiment with $\mathrm{X} 1$ of about 0.773 (temperature of the order of $93^{\circ} \mathrm{C}$ ) and $\mathrm{X} 2$ of -0.634 (time of 11 minutes), the desirability for phenolic content (Y1 close to $34.98 \mathrm{mg}$ GAE/gDM), scavenging activity (Y2 close to $82.10 \%$ ), and the yield of water-soluble polysaccharide (Y3 close to $6.97 \%$ ) is maximal (98.84\%). Hence, the values of the parameters mentioned here before strengthen the probability of having an optimum.

To ensure the predicted result, test rechecking was conducted using the modified optimal conditions of temperature extraction of $94^{\circ} \mathrm{C}$ and decoction time of 10 minutes. Table 6
TABLE 4: Optimal conditions for the extraction process.

\begin{tabular}{lccc}
\hline Variable & Value & Factor & Value \\
\hline $\mathrm{X} 1$ & 0.773326 & Temperature & 93 \\
\hline $\mathrm{X} 2$ & -0.634008 & Time & 11 \\
\hline
\end{tabular}

showed that the experimental results did not vary a lot from the predicted value.

3.2. Physical Chemistry of Optimal Decoction. The aqueous extract represented $51.41 \%$ of the starting mixture (into-water dry material) which was nearly six times the weight of the used dry material (DM). The decoction had an acid $\mathrm{pH}$, about 4.32. It had a liquid appearance (viscosity about $1.33 \mathrm{~Pa} . \mathrm{s}$ ) and a color similar to dark tea infusion, whose characteristics are presented in Table 7.

The total phenolic content, flavonoids, and condensed tannins of the optimal Pelargonium graveolens decoction were measured to reflect their biological property as expressed in DPPH scavenging activity (Table 8).

3.3. Pelargonium graveolens Crude Polysaccharide (CPGP) from Optimal Decoction. In this work, the rheological properties of the CPGP and its preliminary structural analysis were studied.

3.3.1. Rheological Properties of Crude Pelargonium graveolens Polysaccharide. The rheology of Pelargonium graveolens water solutions was studied using the behavior of the apparent viscosity versus the shear rate (Figure 3). The graph showed two areas: the apparent viscosity decreased until a shear rate of $400 \mathrm{~s}^{-1}$, then a constant «unlimited» viscosity was established. This rheological property characterizes the pseudoplastic or shear-thinning behavior $(n<1)$.

The flow behavior index $(\mathrm{n})$ and consistency index $(\mathrm{k})$ values (Table 9) were obtained from the representation of the shear stress versus shear rate according to the power law model (Equation (4), Figure 4). The results showed that the increase in concentration increases the shear stress. Table 9 shows that the flow index decreases with the increase in the concentration of polysaccharide. The statistical analysis revealed that there are no significant differences between all concentrations in terms of index flow.

However, the consistency index values ranged from 322.60 to $382.70 \mathrm{~Pa} \cdot \mathrm{s}^{\mathrm{n}}$. There were significant variations of index consistency of all samples.

3.3.2. Preliminary Structural Analysis. For preliminary CPGP structural analysis purpose, the sugar content by the phenolsulphuric method and the Fourier Transform Infrared spectra were measured.

The total sugar content of CPGP was estimated to be 87.27\% and Figure 5 shows the FTIR spectra of CPGP, exhibiting a large absorption band at around $3350 \mathrm{~cm}^{-1}$, four weak peaks at $2981 \mathrm{~cm}^{-1}, 2370 \mathrm{~cm}^{-1}, 1633 \mathrm{~cm}^{-1}$ and 1410 $\mathrm{cm}^{-1}$. Two intense absorption bands were also observed at $1043 \mathrm{~cm}^{-1}$ and $1087 \mathrm{~cm}^{-1}$. Finally, an absorption band at 

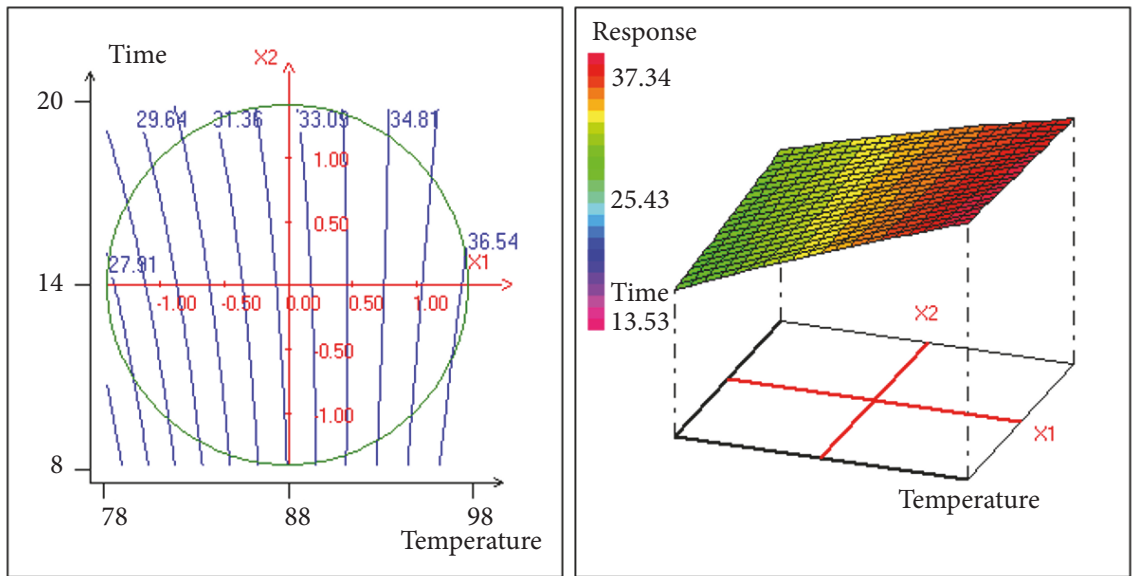

(a)
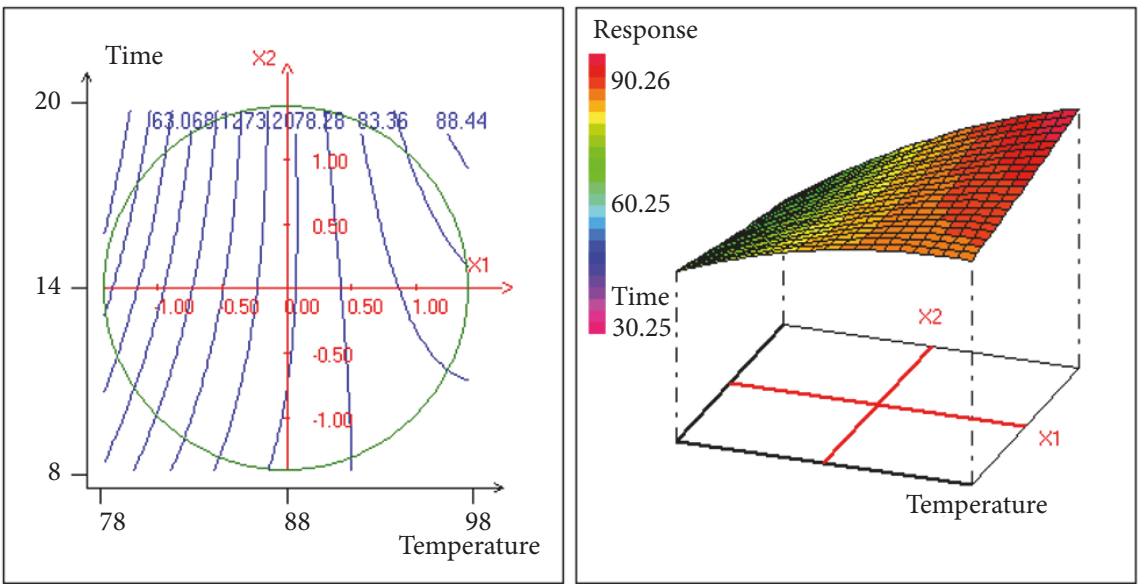

(b)
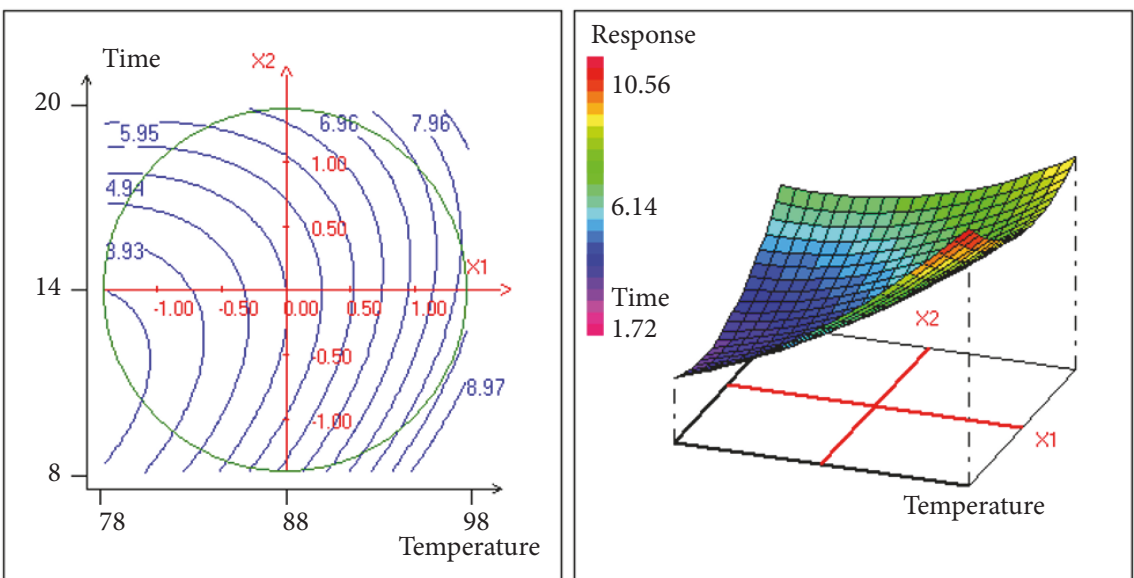

(c)

FIGURE 2: Contour plots and 3D-response surfaces for (a) total phenolic content, (b) DPPH scavenging activity, and (c) CPGP yield, as a function of time and temperature of decoction. 
TABLE 5: Predicted values of the responses at optimal conditions.

\begin{tabular}{lcccccc}
\hline Response & Name & Value & di \% & Weight & di min \% & di max \% \\
\hline Y1 & Total phenolic content (mgGAE/gDM) & $\mathbf{3 4 . 9 8}$ & 99.65 & 1 & 42.51 & 99.65 \\
\hline Y2 & DPPH scavenging activity (\%) & $\mathbf{8 2 . 1 0}$ & 98.43 & 1 & 48.69 \\
\hline Y3 & CPGP yield (\%) & $\mathbf{6 . 9 7}$ & 98.45 & 1 & 63.20 & 98.43 \\
\hline & DESIRABILITY & & 98.84 & & 50.76 & 98.84 \\
\hline
\end{tabular}

di: percentage of calculated desirability.

TABLE 6: Predicted and experimental values of responses at optimal and modified conditions.

\begin{tabular}{|c|c|c|c|c|c|}
\hline & $\begin{array}{c}\text { Extraction } \\
\text { temperature }\left({ }^{\circ} \mathrm{C}\right)\end{array}$ & $\begin{array}{l}\text { Extraction time } \\
(\mathrm{min})\end{array}$ & $\begin{array}{l}\text { Total phenolic content } \\
(\mathrm{mg} \text { GAE/gDM })\end{array}$ & $\begin{array}{l}\text { DPPH scavenging } \\
\text { activity (\%) }\end{array}$ & CPGP yield (\%) \\
\hline Predicted values & 93 & 11 & 34.98 & 82.10 & 6.97 \\
\hline Modified conditions & $94 \pm 2$ & 10 & $33.02 \pm 0.58$ & $68.05 \pm 0.74$ & $6.43 \pm 0.31$ \\
\hline
\end{tabular}

TABle 7: Color (L, a, b) index of the Pelargonium graveolens optimized extract.

\begin{tabular}{lccc}
\hline Sample & L* & $\mathbf{a} *$ & $\mathbf{b} *$ \\
\hline Decoction extract & $18,74 \pm 0,68$ & $2,17 \pm 0,33$ & $11,07 \pm 0,63$ \\
\hline
\end{tabular}

L*: Lightness, a* (-green/+red), b*(-blue/+yellow).

TABLE 8: Chemical content and antioxidant properties of Pelargonium graveolens optimized decoction extract.

\begin{tabular}{lcccc}
\hline Sample & $\begin{array}{c}\text { Total phenolic content } \\
\text { (mgGAE/gDM) }\end{array}$ & $\begin{array}{c}\text { Flavonoids (mg } \\
\text { RE/gDM) }\end{array}$ & $\begin{array}{c}\text { Condensed tannins (mg } \\
\text { CE/gDM) }\end{array}$ & $\begin{array}{c}\text { DPPH scavenging } \\
\text { activity (mg TXE/gDM) }\end{array}$ \\
\hline Optimal decoction extract & $33.01 \pm 0.49$ & $19.76 \pm 0.41$ & $5.31 \pm 0.56$ & $136.10 \pm 0.62$ \\
\hline
\end{tabular}

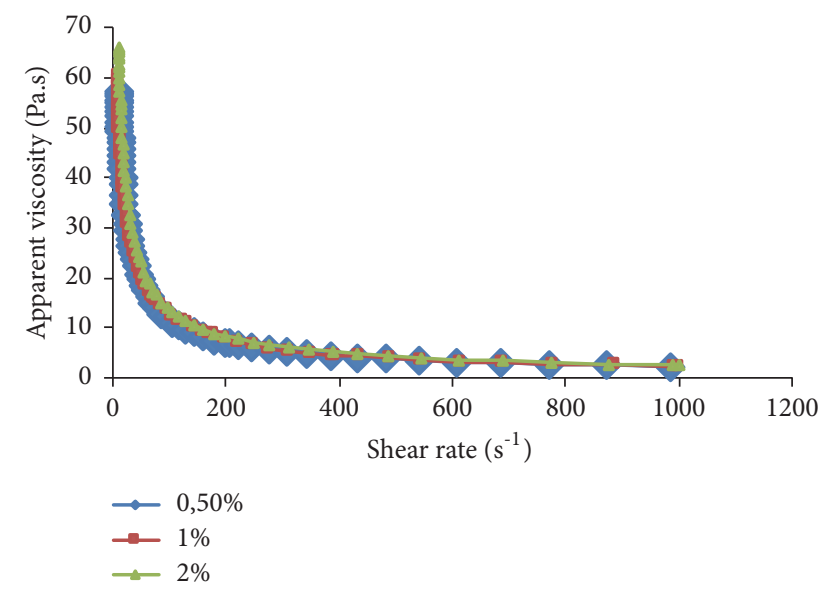

Figure 3: Flow behaviors of crude Pelargonium graveolens polysaccharide at different concentrations $(0.5,1$, and $2 \%$; w/v).

around $877 \mathrm{~cm}^{-1}$ marks the beginning of the «fingerprint» area.

\section{Discussion}

The central composite design was applied to assess the effect of temperature and time on the phenolic content and the antioxidant activity of the decoction. The response surface analysis revealed that the temperature was the most impacting factor. Indeed, the response reached the maximum

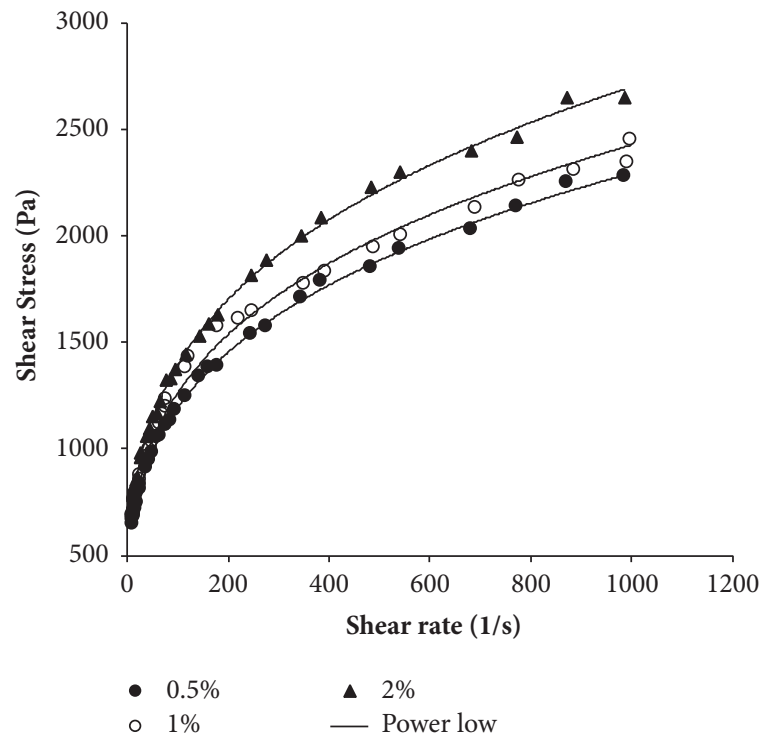

FIgURE 4: Shear stress versus shear rate of crude Pelargoinum graveolens polysaccharide water solution at different concentrations.

value with the increase in temperature. This suggests that the temperature has an effect on plant tissue in improving the phenolic compound extraction [9]. Such finding was recurrent in many studies, stating that the increase in extraction time and temperature enhances the material particles solubility [29] and the diffusion coefficient [30]. 
TABLE 9: Flow behavior index (n) and consistency index (k) of CPGP at different concentrations.

\begin{tabular}{lccc}
\hline Concentration $(\mathbf{w} / \mathbf{v})(\%)$ & $\mathbf{n}$ & $\mathbf{K}\left(\mathbf{P a} \cdot \mathbf{s}^{\mathbf{n}}\right)$ & $\mathbf{R}^{\mathbf{2}}$ \\
\hline 0,5 & $0.283 \pm 0.01^{\mathrm{a}}$ & $322.60 \pm 5.80^{\mathrm{a}}$ & 0.998 \\
\hline 1 & $0.277 \pm 0.02^{\mathrm{b}}$ & $354.60 \pm 7.50^{\mathrm{b}}$ & \\
\hline 2 & $0.279 \pm 0.01^{\mathrm{c}}$ & $382.70 \pm 6.94^{\mathrm{c}}$ & 0.995 \\
\hline The different letters indicated significant difference at $\mathrm{p}<5 \%$ & & & 0.999 \\
\hline
\end{tabular}

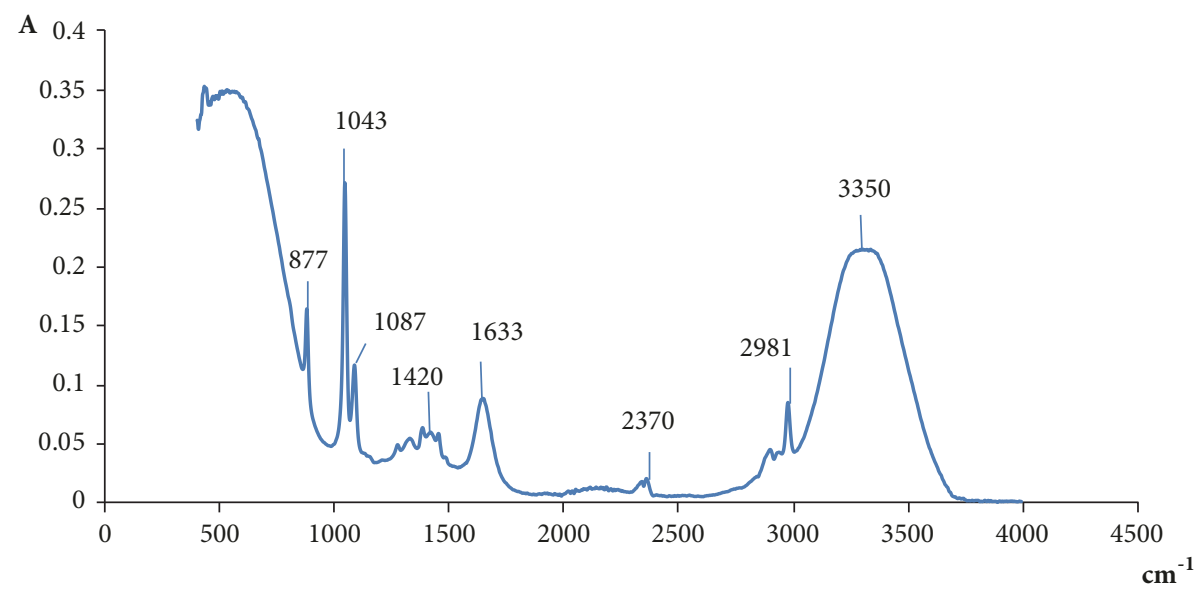

FIGURE 5: Fourier transform infrared spectra of extracted CPGP.

Besides, maintaining a relatively high temperature would increase the yield of the crude Pelargonium graveolens polysaccharide (CPGP). Indeed, different herbal watersoluble polysaccharides extraction studies showed that the extraction temperature varied from $48,7^{\circ} \mathrm{C}$ to $100^{\circ} \mathrm{C}[4,12-$ 14, 31-34]. However, to enhance the macromolecules yield, the time of extraction varied from 29 minutes to 4 hours $[15,33]$. At these extraction conditions, the polysaccharide yield varied from $5,37 \%$ to $18,88 \%$ [12-14, 32-34]. But, since the yield of polysaccharide was the unique matter of these studies, no attention was paid to the activity of other decoction molecules at prolonged heat treatment.

After the validation of optimal extraction conditions, the Pelargonium graveolens decoction at $94^{\circ} \mathrm{C}$ for 10 minutes presented a particular brown color. For tea, this color is desirable [35] and it is influenced by the polyphenol oxidase activity which oxidizes polyphenols to flavonoids, catechins, and brown colored compounds $[35,36]$. For tea infusion, the $\mathrm{L} *$ value is about 59.03; however, for fermented tea infusion it is about 40.25, whereas the lightness of the decoction is much lower (18.74), which may correspond to higher dark colored compounds like those developed through tea fermentation [36]. The redness $(a *)$ and yellowness $(b *)$ of tea infusions (26.17-59.03 and 15.17-25.71, respectively) are, however, higher than color parameters of the optimal decoction (2.17 and 11.07). These parameters could help to differentiate between various geranium species extracts using different processes [36] (infusion, decoction, cold extraction...).

The value of the radical scavenging activity of the optimal Pelargonium graveolens decoction was about 136.1 $\mathrm{mgTXE} / \mathrm{gDM}$ (68.05\%). This finding was explained by the presence of phenolic components (flavonoids and condensed tannins) and mostly flavonoids (19.77 mgRE/gDM) [10, 37]. In addition, the studies of the antioxidant and phenolic profiles of Pelargonium graveolens hydrosols, aqueous extracts, methanol extracts, and essential oils exhibited phenolic contents varying from $54.71 \mathrm{mgGAE} / \mathrm{gDM}$ to 102.44 mgGAE/gDM and scavenging activity up to $83 \%[2,38,39]$.

Roseiro et al. (2013) [9] reported that, under optimum extraction temperature and time $\left(98.5^{\circ} \mathrm{C}\right.$ and $17 \mathrm{~min}$, respectively), carob kibbles decoction exhibited a DPPH scavenging activity of about $85 \%$ and total phenolic content of about 39.5 mg GAE/gDM.

The Pelargonium graveolens water solutions exhibited a pseudoplastic or shear-thinning behavior. Adeli and Savmati (2014) [33] reported that the flow behavior index (n) of $1.5 \%$ w/v Ziziphus lotus fruit polysaccharide solution (WPZL) was about 0.77 , while the same index for the CPGP at $1 \%$ was about 0.27 . This can be explained by the fact that the viscosity of CPGP is higher than that of WZPL at $1 \% \mathrm{w} / \mathrm{v}$ concentration.

The novel water-soluble polysaccharide had a total sugar content of 1.42 time higher than boat-fruited sterculia seeds $(61.17 \%)$ [40] and 1.19 times higher than chickpea polysaccharide [41].

An attempt to a structural analysis of the CPGP by the Fourier Transform Infrared has revealed the presence of a large absorption band at around $3350 \mathrm{~cm}^{-1}$, which may be associated with a hydroxyl group [14]. In fact, as reported by Chien et al. (2015) [42], the peaks from 3200 to $3600 \mathrm{~cm}^{-1}$ may be associated with O-H groups. Furthermore, the band detected at $2981 \mathrm{~cm}^{-1}$ indicated the stretching vibration of C$\mathrm{H}$ groups $[34,42]$. The presence of an absorption band at 1633 
$\mathrm{cm}^{-1}$ suggests the presence of carboxylate stretching group $\left(\mathrm{COO}^{-}\right)$[14] for a band peak around $1605 \mathrm{~cm}^{-1}$. Nevertheless, other studies associated the absorption bands from $1640 \mathrm{~cm}^{-1}$ to $1651 \mathrm{~cm}^{-1}$ with $\mathrm{C}=\mathrm{O}$ groups [42]. However, at $1642 \mathrm{~cm}^{-1}$, the band was associated with water [31]. Moreover, the peak at $1420 \mathrm{~cm}^{-1}$ was assigned to $\mathrm{C}-\mathrm{O}$ stretching vibration [31] and suggests the presence of uronic acid content [13,43]. A strong absorption band was also observed at $1043 \mathrm{~cm}^{-1}$ that could be associated with the $\mathrm{C}-\mathrm{O}-\mathrm{C}$ stretching vibration of glycosidic structure [14] and might suggest the presence of pyranose ring (1043 to $1087 \mathrm{~cm}^{-1}$ ) [31] or even furanose [34, 44].

The obtained bands at $890 \mathrm{~cm}^{-1}$ suggest the presence of the $\beta$-glycosidic bond [42] or $\beta$-D-glucan [45]. It was also reported that the absorption bands between 810 and $870 \mathrm{~cm}^{-1}$ could suggest the presence of mannan in the studied sample $[42,46]$.

\section{Conclusion}

The response surface methodology was used in this study to improve the antioxidant potential of the decoction of Pelargonium graveolens and to enhance the yield of the polysaccharide extraction. The extraction temperature had a linear effect on the different responses and the extraction time had a quadratic effect only on the polysaccharide yield. Besides, there was no interaction between the two extraction parameters. The optimal extraction conditions were obtained: extraction temperature $\left(93^{\circ} \mathrm{C}\right)$ and extraction time $(11 \mathrm{~min})$. Under these conditions, different process responses were as follows: the phenolic content was $33.02 \%$, the radical scavenging activity was $68.05 \%$, and the CPGP yield was $6.43 \%$. These results are in good agreement with the predicted values.

The crude Pelargonium graveolens polysaccharide solutions were found to exhibit shear-thinning non-Newtonian flow behavior for concentrations above $0.5 \%(\mathrm{w} / \mathrm{v})$. The obtained results suggest that the CPGP rheological characteristics are suitable for applications in many industries, especially food. Moreover, the values of optimal conditions showed that decoction operation could have multiple uses, especially for consuming less energy.

\section{Data Availability}

The data used to support the findings of this study are available from the corresponding author upon request.

\section{Conflicts of Interest}

The authors declare that they have no conflicts of interest.

\section{Acknowledgments}

This work has been presented at the Biochemistry and Microbiology Applied Technologies International Congress (BMAT 2017). The authors gratefully acknowledge the committee of this event.

\section{References}

[1] M. N. Boukhatem, F. Saidi, M. S. Hamaidi, Y. Hakim, and M. Mekarnia, "Culture et exploitation industrielle du géranium rosat (Pelargonium graveolens) en Algérie: état des lieux et perspectives," Phytothérapie, vol. 9, no. 5, pp. 304-309, 2011.

[2] S. Ćavar and M. Maksimović, "Antioxidant activity of essential oil and aqueous extract of Pelargonium graveolens L'Her," Food Control, vol. 23, no. 1, pp. 263-267, 2012.

[3] D. Prasad, A. Singh, K. P. Singh, S. Bist, A. Tewari, and U. P. Singh, "The role of phenolic compounds in disease resistance in geranium," Archives of Phytopathology and Plant Protection, vol. 43, no. 7, pp. 615-623, 2010.

[4] A. B. Hsouna and N. Hamdi, "Phytochemical composition and antimicrobial activities of the essential oils and organic extracts from pelargonium graveolens growing in Tunisia," Lipids in Health and Disease, vol. 11, article no. 167, 2012.

[5] M. G. Jinukuti and A. Giri, "Antimicrobial activity of phytopharmaceuticals for prevention and cure of diseases," Ann. Phytomed, vol. 2, no. 2, pp. 28-46, 2013.

[6] M. N. Boukhatem, A. Kameli, and F. Saidi, "Essential oil of Algerian rose-scented geranium (Pelargonium graveolens): Chemical composition and antimicrobial activity against food spoilage pathogens," Food Control, vol. 34, no. 1, pp. 208-213, 2013.

[7] M. E. I. Badawy and S. A. M. Abdelgaleil, "Composition and antimicrobial activity of essential oils isolated from Egyptian plants against plant pathogenic bacteria and fungi," Industrial Crops and Products, vol. 52, pp. 776-782, 2014.

[8] L. Bosson and G. Dietz, Hydrotherapy: Floral water therapy [L'hydrolathérapie : thérapie des eaux florales] Frensh. Coll. Douce Alternative - Ed Amyris, Bruxelles, 3e trimestre, 2005.

[9] L. B. Roseiro, C. S. Tavares, J. C. Roseiro, and A. P. Rauter, "Antioxidants from aqueous decoction of carob pods biomass (Ceretonia siliqua L.): Optimisation using response surface methodology and phenolic profile by capillary electrophoresis," Industrial Crops and Products, vol. 44, pp. 119-126, 2013.

[10] N. Martins, L. Barros, C. Santos-Buelga, M. Henriques, S. Silva, and I. C. F. R. Ferreira, "Decoction, infusion and hydroalcoholic extract of Origanum vulgare L.: different performances regarding bioactivity and phenolic compounds," Food Chemistry, vol. 158, pp. 73-80, 2014.

[11] A. E. Panyoo, T. Boudjeko, A. L. Woguia et al., "Optimization of Variables for Aqueous Extraction of Gum from Grewia mollis Powder," Journal of Polymers, vol. 2014, Article ID 926850, 10 pages, 2014.

[12] M. Chouaibi, L. Rezig, K. B. Daoued, N. Mahfoudhi, H. Bouhafa, and S. Hamdi, "Extraction of polysaccharide from zizyphus lotus fruits," International Journal of Food Engineering, vol. 8, no. 3, 2012.

[13] Z. Ye, W. Wang, Q. Yuan et al., "Box-Behnken design for extraction optimization, characterization and in vitro antioxidant activity of Cicer arietinum L. hull polysaccharides," Carbohydrate Polymers, vol. 147, pp. 354-364, 2016.

[14] K. Mkadmini Hammi, M. Hammami, C. Rihouey, D. Le Cerf, R. Ksouri, and H. Majdoub, "Optimization extraction of polysaccharide from Tunisian Zizyphus lotus fruit by response surface methodology: Composition and antioxidant activity," Food Chemistry, vol. 212, pp. 476-484, 2016.

[15] C. Chen, B. Zhang, Q. Huang, X. Fu, and R. H. Liu, "Microwaveassisted extraction of polysaccharides from Moringa oleifera 
Lam. leaves: Characterization and hypoglycemic activity," Industrial Crops and Products, vol. 100, pp. 1-11, 2017.

[16] X. Guo, X. Zou, and M. Sun, "Optimization of extraction process by response surface methodology and preliminary characterization of polysaccharides from Phellinus igniarius," Carbohydrate Polymers, vol. 80, no. 2, pp. 345-350, 2010.

[17] Y.-Z. Miao, Q. Lin, Y. Cao, G.-H. He, D.-R. Qiao, and Y. Cao, "Extraction of water-soluble polysaccharides (WSPS) from Chinese truffle and its application in frozen yogurt," Carbohydrate Polymers, vol. 86, no. 2, pp. 566-573, 2011.

[18] S. M. A. Razavi, S. A. Mortazavi, L. Matia-Merino, S. H. Hosseini-Parvar, A. Motamedzadegan, and E. Khanipour, "Optimisation study of gum extraction from Basil seeds (Ocimum basilicum L.)," International Journal of Food Science \& Technology, vol. 44, no. 9, pp. 1755-1762, 2009.

[19] V. L. Singleton and J. A. Rossi, "Colorimetry of total phenolics with phosphomolybdic-phosphotungstic acid reagents," American Journal of Enology and Viticulture, vol. 16, pp. 144-158, 1965.

[20] A. Djeridane, M. Yousfi, B. Nadjemi, D. Boutassouna, P. Stocker, and N. Vidal, "Antioxidant activity of some Algerian medicinal plants extracts containing phenolic compounds," Food Chemistry, vol. 97, no. 4, pp. 654-660, 2006.

[21] B. Sun, J. M. Ricardo-da-Silva, and I. Spranger, "Critical factors of vanillin assay for catechins and proanthocyanidins," Journal of Agricultural and Food Chemistry, vol. 46, no. 10, pp. 42674274, 1998.

[22] A. A. Anton, K. A. Ross, O. M. Lukow, R. G. Fulcher, and S. D. Arntfield, "Influence of added bean flour (Phaseolus vulgaris L.) on some physical and nutritional properties of wheat flour tortillas," Food Chemistry, vol. 109, no. 1, pp. 33-41, 2008.

[23] P. B. Pathare, U. L. Opara, and F. A.-J. Al-Said, "Colour Measurement and Analysis in Fresh and Processed Foods: A Review," Food and Bioprocess Technology, vol. 6, no. 1, pp. 3660, 2013.

[24] C. Chen, L.-J. You, A. M. Abbasi, X. Fu, and R. H. Liu, "Optimization for ultrasound extraction of polysaccharides from mulberry fruits with antioxidant and hyperglycemic activity in vitro," Carbohydrate Polymers, vol. 130, pp. 122-132, 2015.

[25] M. Dubois, K. A. Gilles, J. K. Hamilton, P. A. Rebers, and F. Smith, "Colorimetric method for determination of sugars and related substances," Analytical Chemistry, vol. 28, no. 3, pp. 350356, 1956

[26] C. Hoinard, Complete factorial plans [Les plans factoriels complets] Frensh. Power Point Presentation, 2010, http://unt-ori2.crihan.fr/ unspf/2010_Tours_Hoinard_PlansExperimentaux/res/1PFCdiapo .pdf.

[27] K. Khoder, Optimization of microwave components by the technique of surface planes [Optimisation de composants hyperfréquences par la technique des plans à surfaces de réponses] Frensh, Thesis at Université de Limoges, France, 2011, http://www.theses.fr/2011LIMO4039.

[28] Mnif I, S Chaabouni-Ellouze, and D Ghribi, "Optimization of the Nutritional Parameters for Enhanced Production of B. subtilis SPB1 Biosurfactant in Submerged Culture Using Response Surface Methodology," Biotechnology Research International, vol. 2012, Article ID 795430, 8 pages, 2012.

[29] C. Messaoud, A. Laabidi, and M. Boussaid, "Myrtus communis L. Infusions: The Effect of Infusion Time on Phytochemical Composition, Antioxidant, and Antimicrobial Activities," Journal of Food Science, vol. 77, no. 9, pp. C941-C947, 2012.

[30] M. Masmoudi, S. Besbes, M. Chaabouni et al., "Optimization of pectin extraction from lemon by-product with acidified date juice using response surface methodology," Carbohydrate Polymers, vol. 74, no. 2, pp. 185-192, 2008.

[31] Y. Song, B. Du, T. Zhou et al., "Optimization of extraction process by response surface methodology and preliminary structural analysis of polysaccharides from defatted peanut (Arachis hypogaea) cakes," Carbohydrate Research, vol. 346, no. 2, pp. 305-310, 2011.

[32] C. Zhu and X. Liu, "Optimization of extraction process of crude polysaccharides from Pomegranate peel by response surface methodology," Carbohydrate Polymers, vol. 92, no. 2, pp. 11971202, 2013.

[33] M. Adeli and V. Samavati, "Studies on the steady shear flow behavior and chemical properties of water-soluble polysaccharide from Ziziphus lotus fruit," International Journal of Biological Macromolecules, vol. 72, pp. 580-587, 2015.

[34] F. Jafari, F. Khodaiyan, H. Kiani, and S. S. Hosseini, "Pectin from carrot pomace: Optimization of extraction and physicochemical properties," Carbohydrate Polymers, vol. 157, pp. 1315-1322, 2017.

[35] C.-K. Hsu, W.-H. Lin, and H.-W. Yang, "Influence of preheating on antioxidant activity of the water extract from black soybean and color and sensory properties of black soybean decoction," Journal of the Science of Food and Agriculture, vol. 93, no. 15, pp. 3883-3890, 2013.

[36] Y. Liang, J. Lu, L. Zhang, S. Wu, and Y. Wu, "Estimation of tea quality by infusion colour difference analysis," Journal of the Science of Food and Agriculture, vol. 85, no. 2, pp. 286-292, 2005.

[37] M. Dimitrova, D. Mihaylova, A. Popova, and J. Alexieva, "Phenolic profile, antibaterial and antioxidant activity of Pelargonium graveolens leaves' extracts," Scientific Bulletin. Series F. Biotech, vol. 19, pp. 130-135, 2015.

[38] W. Mnif, W. Dhifi, N. Jelali, H. Baaziz, A. Hadded, and N. Hamdi, "Characterization of leaves essential oil of pelargonium graveolens originating from tunisia: Chemical composition, antioxidant and biological activities," Journal of Essential Oil Bearing Plants, vol. 14, no. 6, pp. 761-769, 2011.

[39] M. Boukhris, M. Bouaziz, I. Feki, H. Jemai, A. El Feki, and S. Sayadi, "Hypoglycemic and antioxidant effects of leaf essential oil of Pelargonium graveolens L'Hér. in alloxan induced diabetic rats," Lipids in Health and Disease, vol. 11, no. 81, pp. 1-10, 2012.

[40] Y. Wu, S. W. Cui, J. Tang, and X. Gu, "Optimization of extraction process of crude polysaccharides from boat-fruited sterculia seeds by response surface methodology," Food Chemistry, vol. 105, no. 4, pp. 1599-1605, 2007.

[41] A. Mokni Ghribi, A. Sila, I. Maklouf Gafsi et al., "Structural, functional, and ACE inhibitory properties of water-soluble polysaccharides from chickpea flours," International Journal of Biological Macromolecules, vol. 75, pp. 276-282, 2015.

[42] R.-C. Chien, M.-T. Yen, Y.-H. Tseng, and J.-L. Mau, "Chemical characteristics and anti-proliferation activities of Ganoderma tsugae polysaccharides," Carbohydrate Polymers, vol. 128, article no. 9830, pp. 90-98, 2015.

[43] H. Hu, H. Liang, and Y. Wu, "Isolation, purification and structural characterization of polysaccharide from Acanthopanax brachypus," Carbohydrate Polymers, vol. 127, pp. 94-100, 2015.

[44] W. Wang, X. Ma, Y. Xu et al., "Ultrasound-assisted heating extraction of pectin from grapefruit peel: Optimization and comparison with the conventional method," Food Chemistry, vol. 178, pp. 106-114, 2015.

[45] Y. Peng, L. Zhang, F. Zeng, and J. F. Kennedy, "Structure and antitumor activities of the water-soluble polysaccharides from 
Ganoderma tsugae mycelium," Carbohydrate Polymers, vol. 59, no. 3, pp. 385-392, 2005.

[46] M. Mathlouthi and J. L. Koenig, "ChemInform Abstract: Vibrational Spectra of Carbohydrates," Chem. Biochem, vol. 44, no. C, pp. 7-89, 1987. 


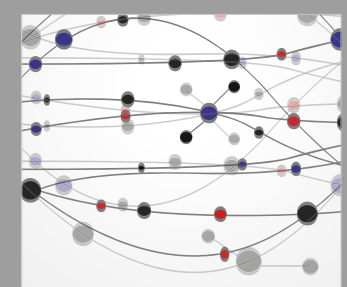

The Scientific World Journal
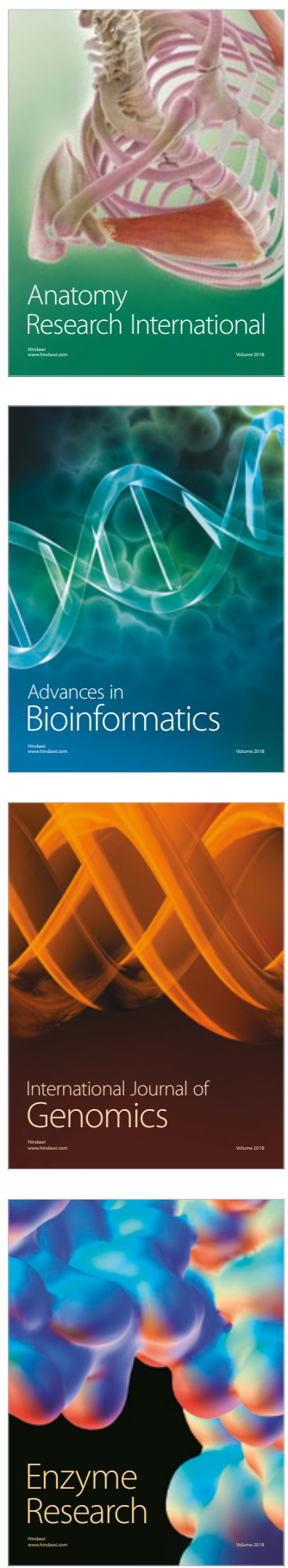
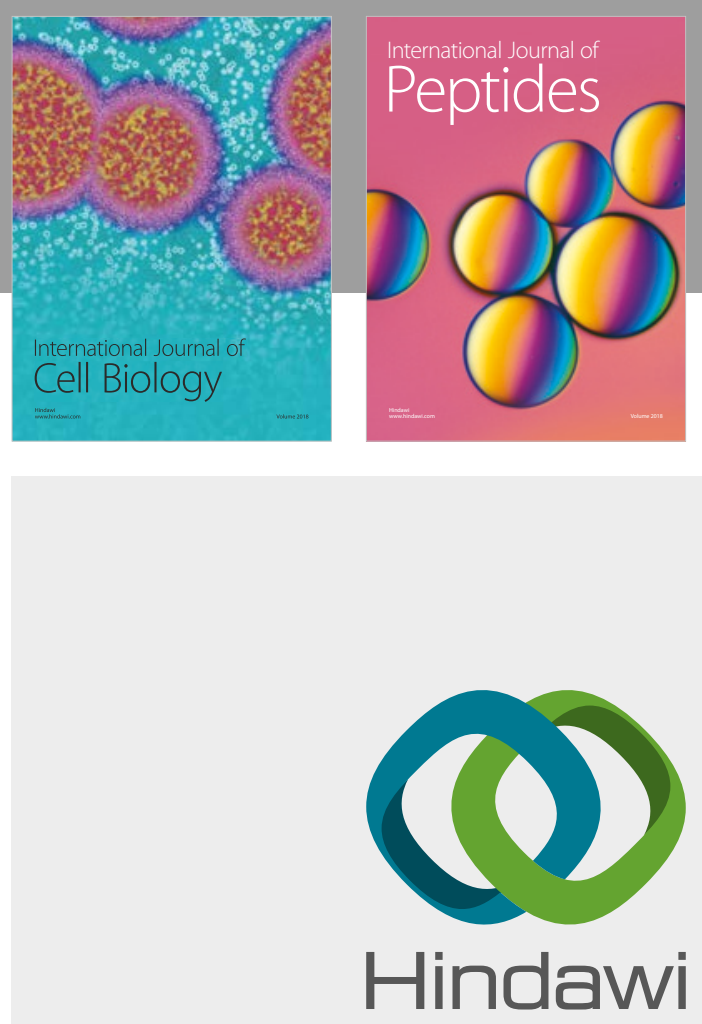

Submit your manuscripts at

www.hindawi.com
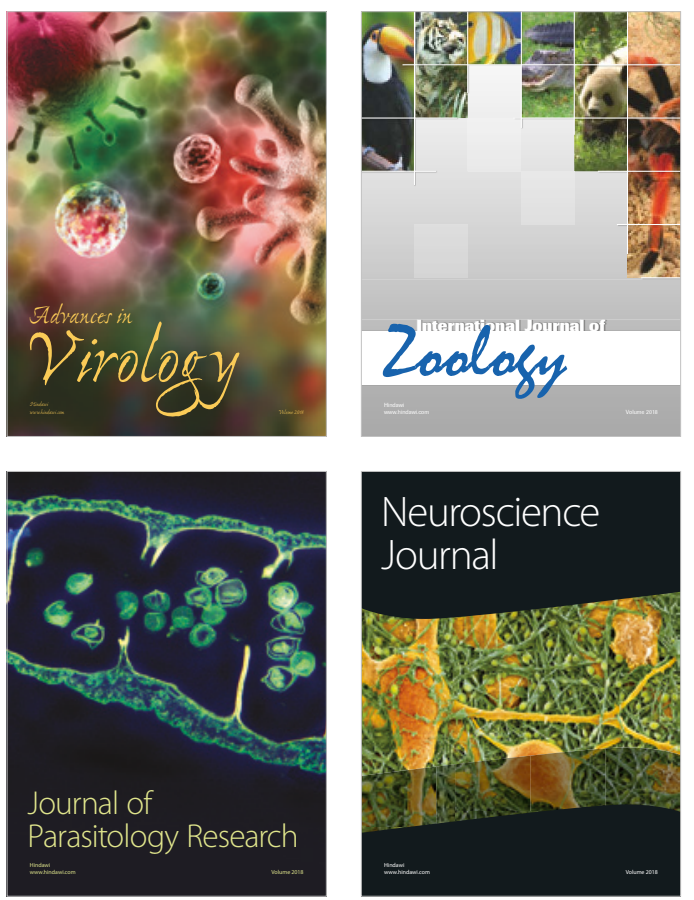
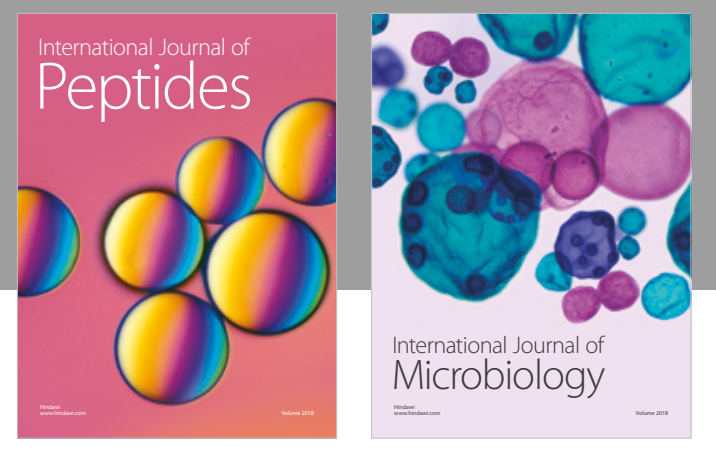

nternational Journal of Microbiology
Journal of
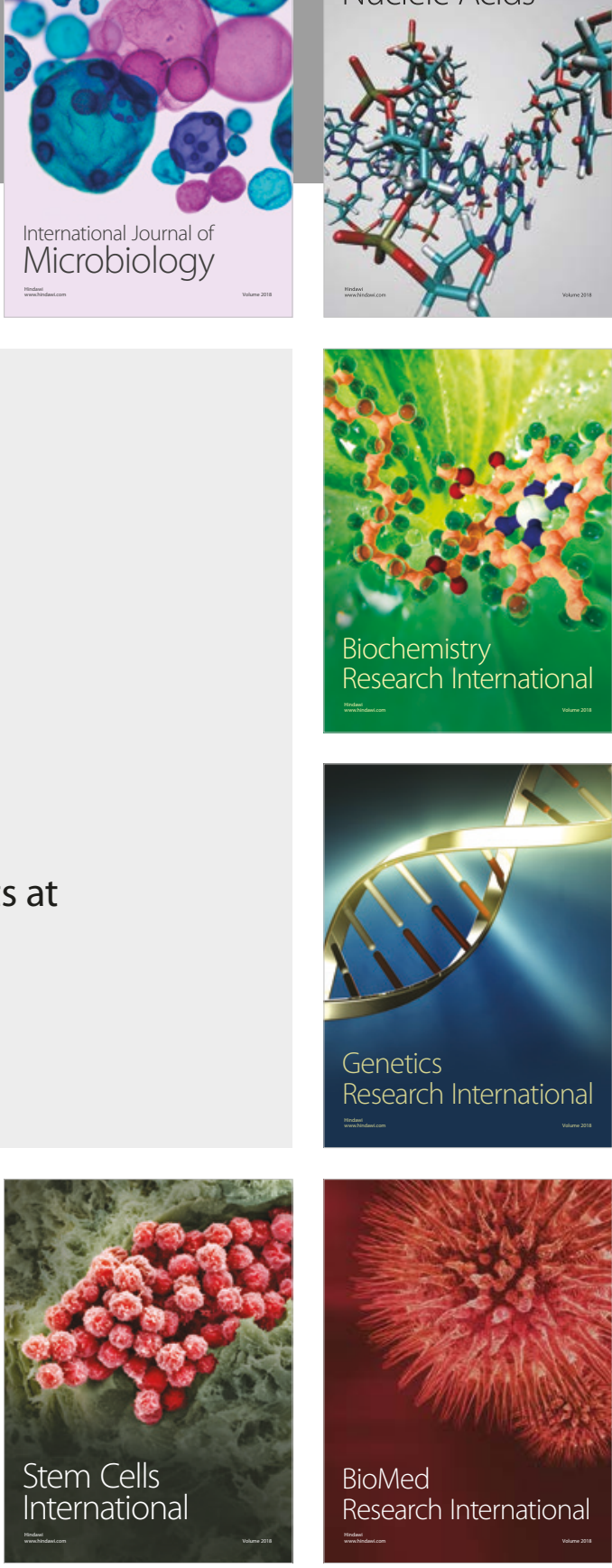
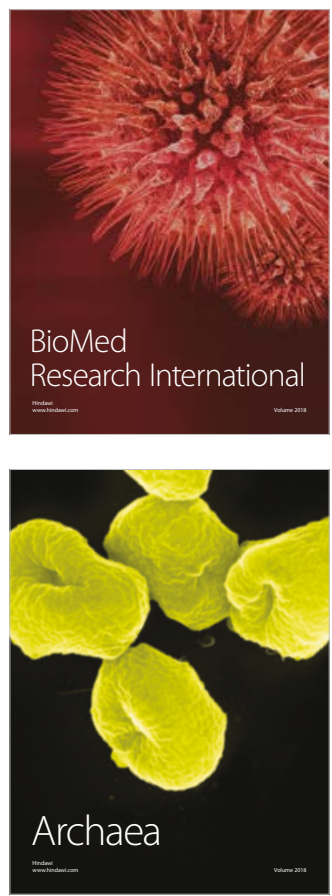